\title{
Superior thermal conductivity of transparent polymer nanocomposites with a crystallized alumina membrane
}

\author{
Md. Poostforush, H. Azizi* \\ Plastics Dept., Processing Faculty, Iran Polymer and Petrochemical Institute, P.O.Box.14965/115, Tehran, Iran
}

Received 12 October 2013; accepted in revised form 14 December 2013

\begin{abstract}
The properties of novel thermoconductive and optically transparent nanocomposites have been reported. The composites were prepared by the impregnation of thermoset resin into crystallized anodic aluminum oxide (AAO). Crystallized AAO synthesized by annealing amorphous AAO membrane at $1200^{\circ} \mathrm{C}$. Although through-plane thermal conductivity of nanocomposites improved up to $1.13 \mathrm{~W} \cdot \mathrm{m}^{-1} \cdot \mathrm{K}^{-1}$ (39 vol\% alumina) but their transparency was preserved $\left(T_{\lambda 550 \mathrm{~nm}} \sim 72 \%\right)$. Integrated annealed alumina phase, low refractive index mismatch between resin and alumina and formation of nano-optical fibers through the membrane resulted in such marvel combination. This report shows a great potential of these types of nanocomposites in 'heat management' of lightening devices.
\end{abstract}

Keywords: nanocomposites, thermal conductivity, transparent, anodized alumina

\section{Introduction}

Heat management is a critical issue during the service life of electronic devices. Many applications would benefit from the use of polymers with high thermal conductivity. To have efficient devices, the heat released from itself must be managed to reduce afterwards operating temperature. However, the use of polymeric composite heat sinks is one of the conventional methods to manage the heat in electronic devices. Overheating of LED lightening instruments can decrease their shelf life, quality and amount of light [1]. Heat dissipation through transparent optical parts in electronic devices can suggest new approaches in heat management filed. Incorporation of thermally-conductive micro size ceramics such as silicon carbide, Aluminum Nitride, Boron nitride (BN) and $\mathrm{Al}_{2} \mathrm{O}_{3}$ to polymeric matrix can enhance thermal conductivity [2-10]. Incorporation of high filler contents of these micro type fillers to get moderate heat dissipation is usual. Addition of limited amount of fillers to transparent polymers will dam- age their optical transmittance. However in some special applications the transparency is also an important factor for polymer composites. Addition of nano fillers to transparent polymeric matrix can balance both transparency and thermal properties. Based on our knowledge there are few publications on using transparent polymeric composites for heat management applications. Transparent boron nitride nanotubes (BNNT)/ polyvinyl formal composites fabricated by Terao et al. [11]. Thermal conductivity of PVF composites contain $1 \mathrm{wt} \%$ of filler raised by rate of $156 \%$ and reached to $0.26 \mathrm{~W} \cdot \mathrm{m}^{-1} \cdot \mathrm{K}^{-1}$. In another report [12] these authors aligned BNNT in PVA by electrospinning method. Thermal conductivity of transparent composites reached to $0.54 \mathrm{~W} \cdot \mathrm{m}^{-1} \cdot \mathrm{K}^{-1}$ along the BNNT orientation $(10 \mathrm{wt} \%)$. Greatest through-plane thermal conductivity was claimed in that investigation related to randomly dispersed BNNT composites in PVA $\left(0.28 \mathrm{~W} \cdot \mathrm{m}^{-1} \cdot \mathrm{K}^{-1}\right)$. It should be noted that in none of above reports, authors did not dislcose the optical

\footnotetext{
${ }^{*}$ Corresponding author, e-mail: h.azizi@ippi.ac.ir

(C) BME-PT
} 
transmittance. Shimazaki et al. [13] fabricated transparent $\left(T_{\lambda 550 \mathrm{~nm}}: 72.6 \%\right)$ Epoxy/Cellulose nanofibers $(\mathrm{CNFs})$ with high in-plane thermal conductivity $\left(1 \mathrm{~W} \cdot \mathrm{m}^{-1} \cdot \mathrm{K}^{-1}\right.$ and Through-plane: $\left.0.23 \mathrm{~W} \cdot \mathrm{m}^{-1} \cdot \mathrm{K}^{-1}\right)$. Excellent thermal conductivity of CNFs, small diameter of fibrils $(<50 \mathrm{~nm})$ and low refractive index mismatch between the components can offer such unique combination.

In this letter, transparent nanocomposites were prepared by impregnation of thermoset resin into an annealed AAO membrane. In addition, morphological structure, thermal conductivity and transmittance of nanocomposites were evaluated.

\section{Experimental}

\subsection{Materials}

Commercially available AAO membrane (pore size: $20 \mathrm{~nm}$, Anodisc 47, Whatman, International Ltd, Maidstone, UK) selected as a filler. A mixture of Bisphenol A type epoxy (50 wt \%, KFR-120, Kukdo Chemichal Co. Ltd, Seoul, South Korea) and hardener (50 wt \%, KFH-9590H, Kukdo Chemichal Co. Ltd, Seoul, South Korea) used as a resin. All of the chemicals were used as received. Refractive index of ingredients listed in Table 1.

Table 1. Refractive index (R.I.) of raw materials

\begin{tabular}{|l|c|c|}
\hline \multicolumn{1}{|c|}{ Materials } & R.I. & Ref \\
\hline Amorphous alumina & $1.60-1.67$ & Whatman $[14]$ \\
\hline AAO membrane & 1.63 & {$[15]$} \\
\hline Epoxy & $1.50-1.57$ & {$[13,16]$} \\
\hline
\end{tabular}

\subsection{Sample preparation}

In order to crystallize AAO membrane, we sandwiched them between two alumina plates and located in a furnace (EW-33855-30, Cole-Parmer, Illinois, USA). The temperature was increase at a rate of $3^{\circ} \mathrm{C} \cdot \mathrm{min}^{-1}$ to a target temperature $\left(1200^{\circ} \mathrm{C}\right.$, AAO- 1200 , ramping: $3^{\circ} \mathrm{C} \cdot \mathrm{min}^{-1}$ ) for four hours and then cooled down to room temperature.

Nanocomposites were fabricated by immersion of AAO or AAO-1200 in resin. The impregnated membrane tightly sandwiched by two glass slides and fixed by parallel metal clips and cured at $85^{\circ} \mathrm{C}$ for three hours to get the nanocomposites. Figure 1 shows a graphical scheme of preparation of these nanocomposites. In order to prepare free-standing films, silicon base release agent (FREKOTE 700-

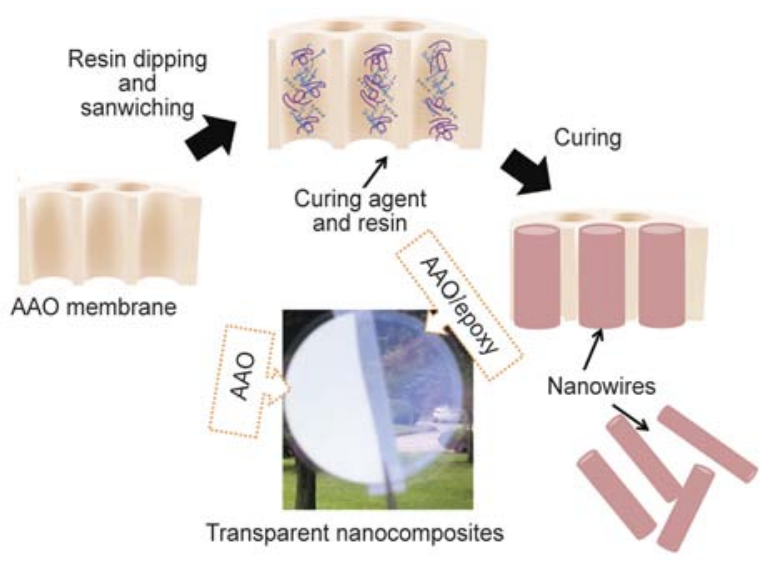

Figure 1. Nanocomposites preparation scheme and related photograph of AAO/epoxy nanocomposites (Glass slides should be added)

NC, Henkel, Hong Kong, China) was applied on the surface of glass before starting the procedure. After curing step, we simply discharged the composites.

\subsection{Characterization and measurements}

\subsubsection{X-ray diffraction}

Powder X-ray diffraction (XRD, D/MAX-2500H, Rigaku, Tokyo, Japan) analysis with $\mathrm{Cu} \mathrm{K} \mathrm{K}_{\alpha 1}=$ $1.54056 \AA$ radiation was used to show the crystallinity enhancement of annealed AAO compare to non-treated AAO membrane. The detector moved step by step $\left(\Delta 2 \theta=0.05^{\circ}\right)$ between 10 to $90^{\circ}$.

\subsubsection{Field emission scanning electron microscopy (FE-SEM)}

A field emission scanning electron microscope (S4500, JEOL, Tokyo, Japan) at an acceleration voltage of $10 \mathrm{kV}$ used to observe morphological features of unannelead, annealed AAO membrane and prepared composites. Samples were Pt coated, using a sputter coater (108Auto, Cressington Scientific, Watford, UK) for 2 min before imaging, to avoid charging during observation.

\subsubsection{Light transmittance}

Light transmittance percentage of composites was measured using UV-Vis spectrophotometer (HP8453, Hewlett Packard, Germany). Two slide glasses were considered as blank for transmittance measurement of all composites which were laminated between two glasses. Laminating between two glasses can limit surface disorders and improve the transmittance of composites. 


\subsubsection{Thermal conductivity}

Through-plane thermal conductivity of nanocomposites can be calculated from thermal diffusivity by using Equation (1):

$K=\alpha \cdot \rho \cdot C_{\mathrm{p}}$

Thermal diffusivity $\left(\alpha\left[\mathrm{mm}^{2} / \mathrm{s}\right]\right)$ was measured using laser flash method in Microflash instrument (LFA-457, NETZSCH, Selb, Germany). Laser flash technique introduced in 1961 by Parker et al. [17]. Laser heat pulses irradiated on the front side of square shape sample; the heat transmitted through the sample thickness direction and measured by an infrared camera. The time to reach the half of the maximum temperature $\left(t_{1 / 2}\right)$ at the back side of the sample was chosen to calculate the heat diffusivity according to the Equation (2):

$\alpha=\frac{1.38 L^{2}}{\pi^{2} t_{1 / 2}}$

Density $\left(\rho\left[\mathrm{g} / \mathrm{cm}^{3}\right]\right)$ gained by electronic densitometer (MD-300S, Alfa Mirage, Tokyo, Japan) and differential scanning calorimeter (N-650, Scinco, Seoul, Korea) used in order to measure the specific heat $\left(C_{\mathrm{p}}[\mathrm{J} /(\mathrm{g} \cdot \mathrm{K})]\right) \cdot 10-15 \mathrm{mg}$ sample was loaded in the $\mathrm{Al}$ pan and the experiments were conducted under nitrogen atmosphere. Optical tightness of transparent free standing films provided by gold sputtering $(200 \mathrm{sec})$ and carbon coating on both sides of samples $(1 \times 1 \mathrm{~mm})$. The specific heats of nanocomposite estimated from those of polymer and AAO in terms of mixing rule: Composites $=\omega_{\text {polymer }}$ Polymer $+\omega_{\mathrm{AAO}} \mathrm{AAO}$, where $\omega$ denotes weight fractions.

\section{Results and discussion}

\subsection{Membrane crystallinity}

XRD graphs of annealed (AAO-1200) and unannealed AAO membrane are shown in Figure 2. As it is clear, unannealed membrane just shows a flat curve (without any characteristic peaks) compared to AAO-1200. Flat appearance of unannealed XRD chart can come from amorphous structure and extremely low intensity of fully amorphous structure sample. On the other hand, AAO-1200 chart shows sharp peaks which can relates to $\theta$-alumina [3]. Annealing of amorphous AAO led to crystallinity enhancement of AAO which later can improve the thermal conductivity of membrane.

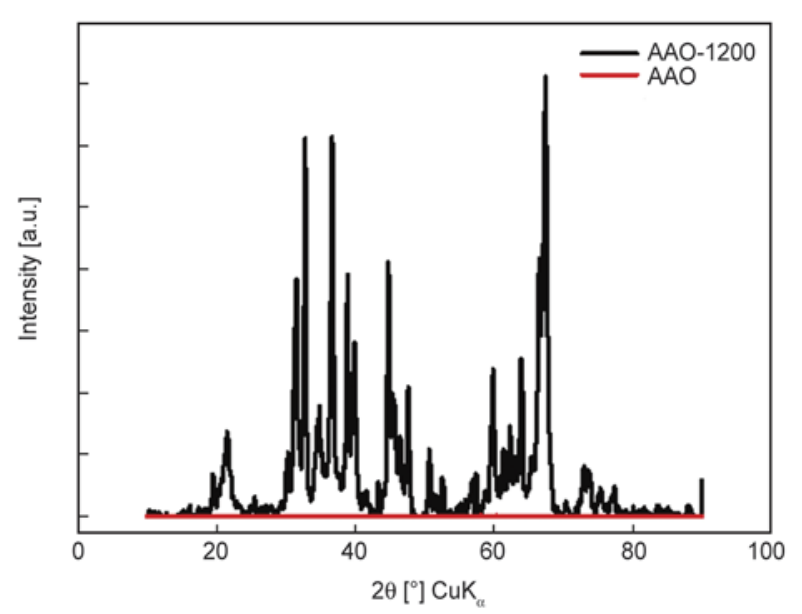

Figure 2. XRD charts of $\mathrm{AAO}$ and annealed $\mathrm{AAO}$ at $1200^{\circ} \mathrm{C}$ (AAO-1200)

\subsection{Morphological characteristics}

Morphology of annealed and unannealed membranes investigated and the micrographs are shown in Figure 3. Unannealed membrane image (Figure $3 \mathrm{a}$ ) is same as typical surface of AAO sheets that contains high pore density and narrow pore size distribution $(\sim 25 \mathrm{~nm})$. Annealing of membrane led to phase transition of amorphous alumina and partially sintering of walls which subsequently reduced the final pores size $(\sim 15 \mathrm{~nm})$ of membrane. The insets show opposite side of membranes before and after annealing. Similar evidences found in opposite side, but it was not significant. In addition, morphological changes in cross section, studied after fracturing the membranes as shown in Figure 3c-3d. Figure $3 \mathrm{c}$ illustrates non interconnected channels of the membrane which extended in parallel fashion through the thickness. As it can be seen, annealing of membrane made disorders on the cylindrical shape walls (Figure 3d). It is worth nothing to say that, there is a great chance for resin to penetrate to this structure and form polymeric nanowires.

The morphological surface of nanocomposites was also investigated and the images illustrated in Figure 4. For both un-annealed (Figure 4a) and annealed (Figure 4b) composites, surface roughness decreased well in comparison with virgin AAO membrane. Figure $4 \mathrm{c}-4 \mathrm{~d}$ shows cross-section of unannealed and annealed composites, respectively. As it is clear, nanowires formed in both types through the sample thickness. 


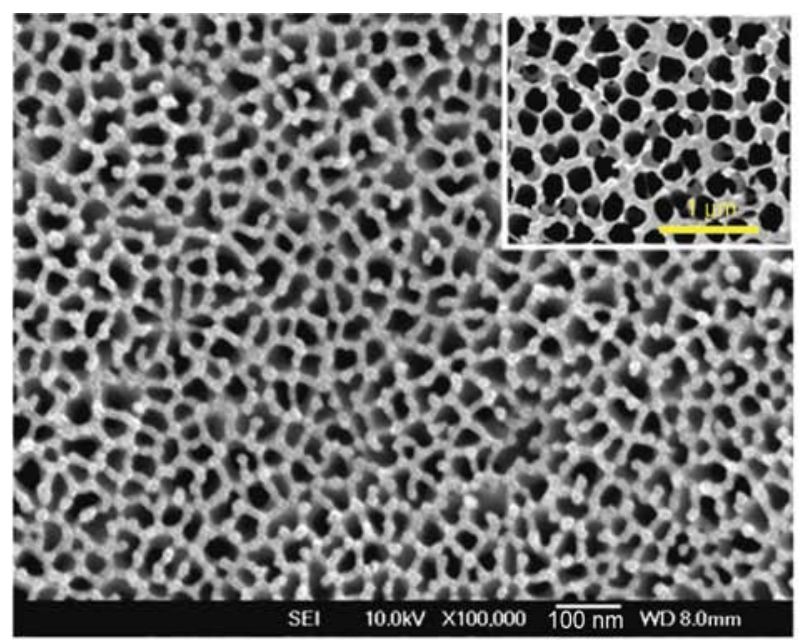

a)

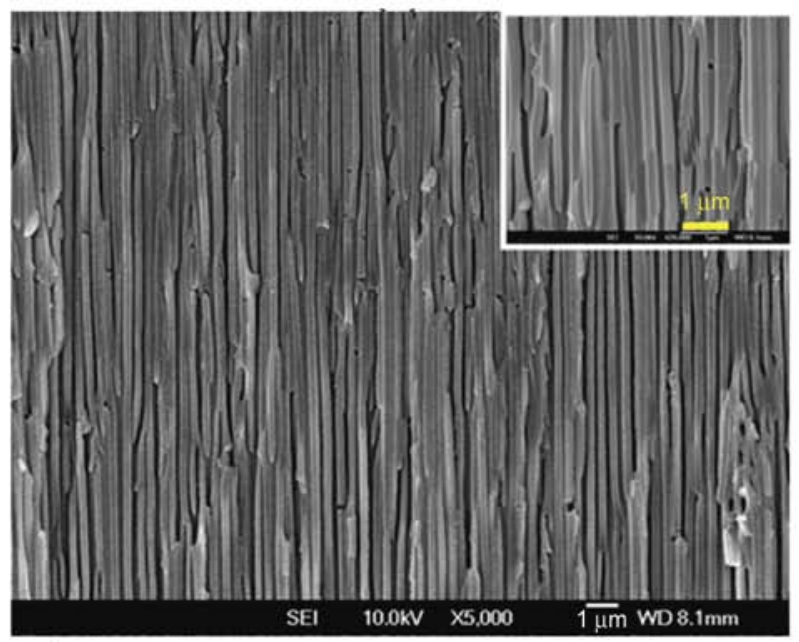

c)

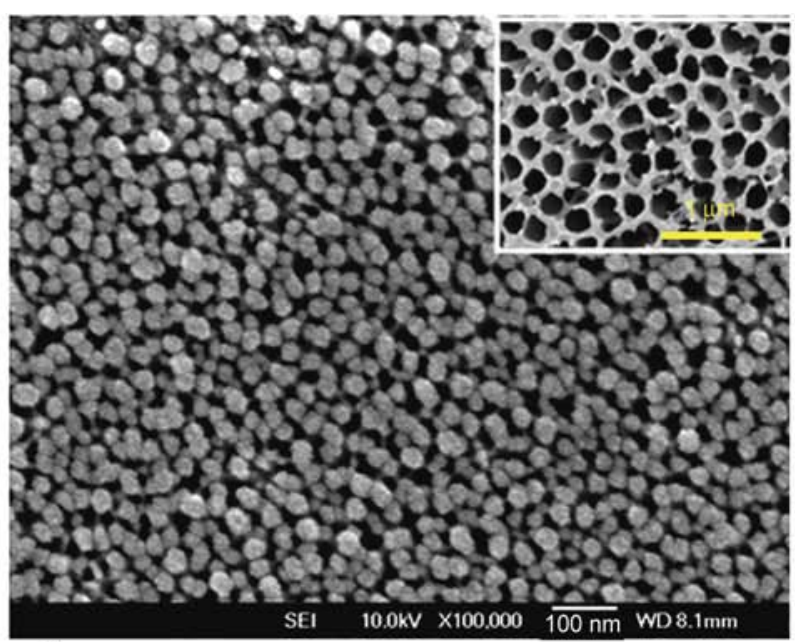

b)

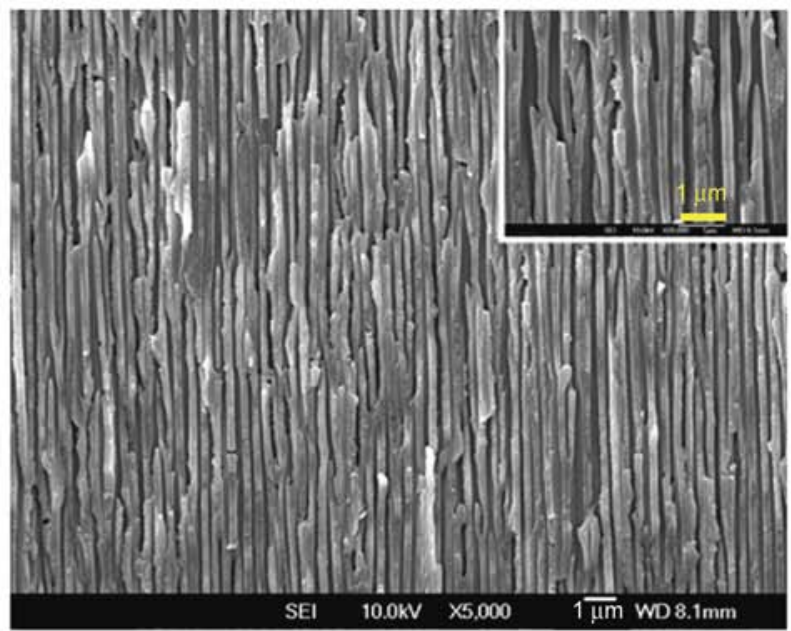

d)

Figure 3. Surface images of (a) unannealed AA sheet, (b) annealed AAO at $1200^{\circ} \mathrm{C}$ and cross sectional images of (c) unannealed AA sheet, (d) annealed $\mathrm{AAO}$ at $1200^{\circ} \mathrm{C}$

\subsection{Light transmittance of nanocomposites}

Light transmittance measured using UV-Visible spectrophotometer and the results are demonstrated in Figure 5. Lack of optical transmission in AAO membrane is due to surface light scattering and limitations for light diffusion through the thickness $(60 \mu \mathrm{m})$ of membrane. In transparent organic-inorganic composites, filler size, composite surface roughness and refractive index $(R I)$ difference [18] between inorganic phase and matrix might be responsible for their transparency. The light transmission percentages of annealed and unannealed composites are demonstrated in Figure 5a. Transparency $\left(T_{\lambda 550 \mathrm{~nm}}[\%]\right)$ of unannealed Anodisc is about $0.04 \%$ while for unannealed AAO/epoxy nanocomposites the transparency reached up to $87.90 \%$. As it is clear from Figure $5 \mathrm{~b}$, letters behind the free standing AAO-1200/epoxy in the background (nodisc 25) can be seen completely, confirming that the nano- composites are transparent. Filling pores by transparent resin, which has low refractive index mismatch with membrane, can result in transparent films. As a result of capillary forces [19], precursor successfully penetrated (Figure 3 ) into the pores and solidified after polymerization. Impregnated thermoset formed nanowires in channels after crosslinking. Nanowires can discharge by dissolving alumina template in nanocomposite at $6 \mathrm{M} \mathrm{NaOH}$. They (Figure 5c) can act as polymeric optical fibers which helped the light to diffuse through the thickness. In addition, it is worth nothing that, prepared composites have high transparency near IR spectral region. Annealing of AAO membrane led to decrement of nanocomposite transparency (AAO-1200, $T_{\lambda 550 \mathrm{~nm}}$ : $72.6 \%$ ) compared to AAO/epoxy. As it was mentioned, the sintering of the membrane [3] would happen due to phase transition of amorphous alumina. Introducing of these types of disorders (Fig- 


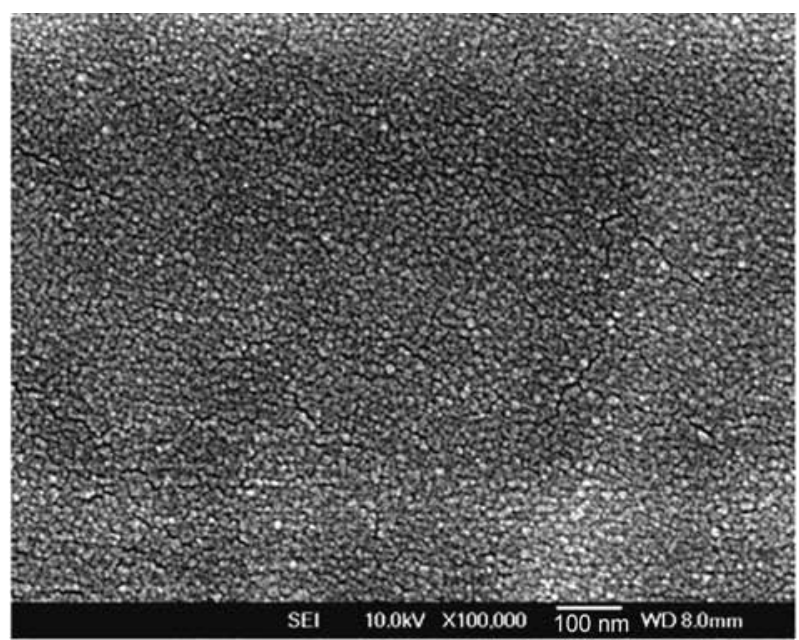

a)

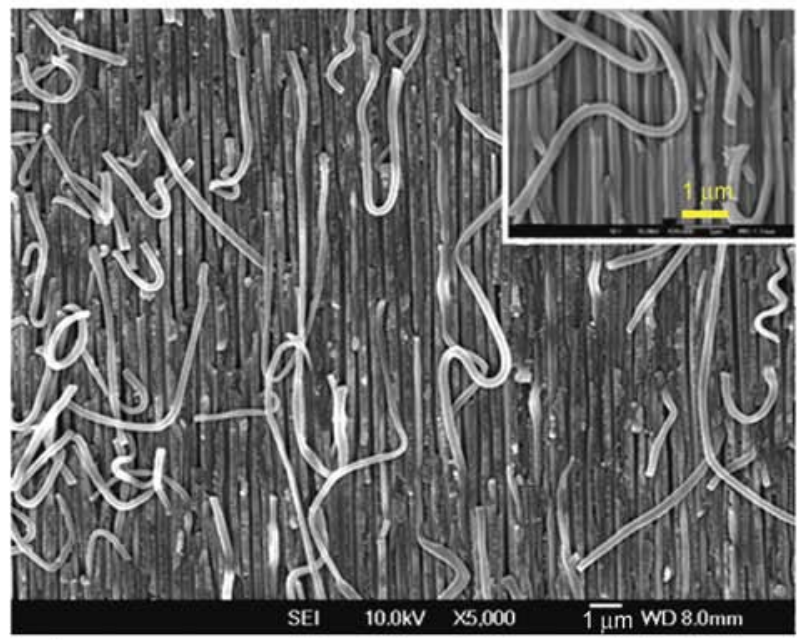

c)

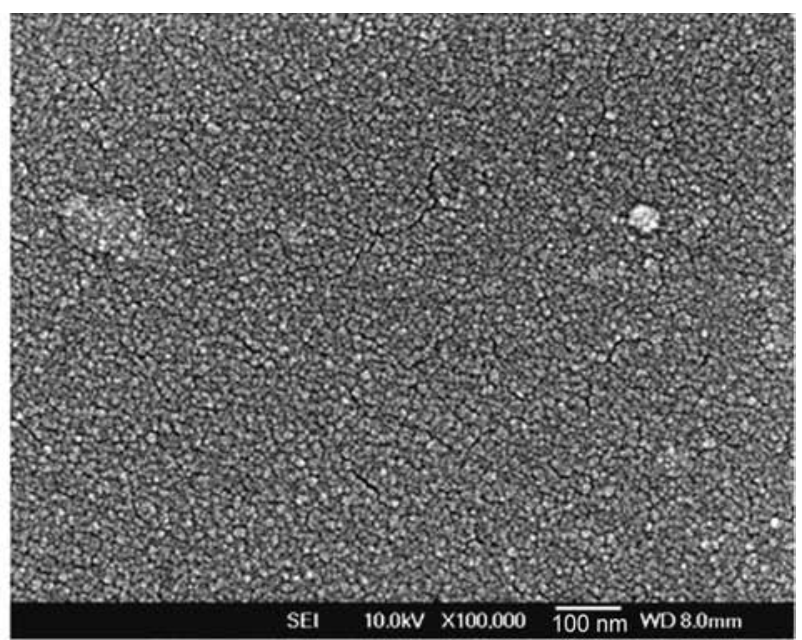

b)

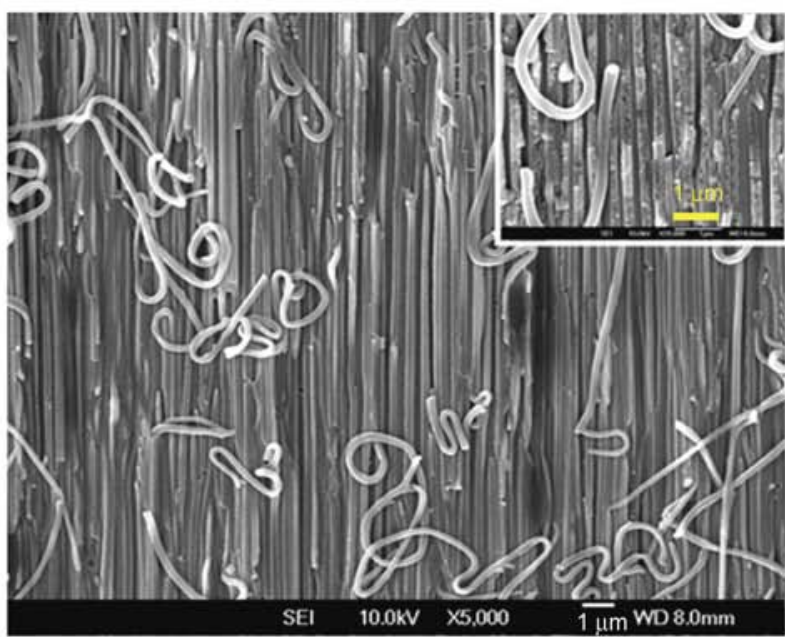

d)

Figure 4. Surface images of nanocomposites with (a) an unannealed AAO/epoxy, (b) AAO-1200/epoxy and cross sectional images of (c) an unannealed AAO/epoxy and (d) AAO-1200/epoxy samples

ure $2 \mathrm{~b}$ and Figure $2 \mathrm{~d}$ ) can decline pore size and subsequently decrease the transparency of AAO1200/epoxy nanocomposites. In addition, prepared AAO-1000/epoxy nanocomposites shows similar optical results as we found in the case of AAO1200/epoxy nanocomposites.

\subsection{Thermal conductivity of nanocomposites}

High through-plane thermal conductivity of transparent nanocomposites is one of the interesting areas in optical electronics. The highest improvement in through plane thermal conductivity of transparent polymer composites is $53.33 \%$ ( 0.18 to $0.23 \mathrm{~W} \cdot \mathrm{m}^{-1} \cdot \mathrm{K}^{-1}$ ) which reported by Shimazaki et al. [13] for cellulose nano-fiber based nanocomposites. Thermal conductivity of unannealed $\mathrm{AAO} /$ epoxy composites attained to $0.25 \mathrm{~W} \cdot \mathrm{m}^{-1} \cdot \mathrm{K}^{-1}$. Higher thermal conductivity of AAO compared to epoxy $\left(0.15 \mathrm{~W} \cdot \mathrm{m}^{-1} \cdot \mathrm{K}^{-1}\right)$ can suggest this improve- ment. Thermal conductivity of annealed-AAO/ epoxy nanocomposites, calculated and the results reported in Table 2. The thickness and volume contents of filler in nanocomposites mentioned too. As it was expected [3] incorporation of annealed AAO membranes can enhance the total thermal conductivity of composites. Thermal conductivity of epoxy/ AAO-1200 samples enhanced up to $1.13 \mathrm{~W} \cdot \mathrm{m}^{-1} \cdot \mathrm{K}^{-1}$. Based on our knowledge this is the highest throughplane thermal conductivity of transparent polymer

Table 2. Thermal conductivity (TC), filler contents and thickness of epoxy nanocomposites

\begin{tabular}{|l|c|c|c|}
\hline \multicolumn{1}{|c|}{ Sample } & $\begin{array}{c}\text { Filler content } \\
{[\mathbf{v o l \% ]}}\end{array}$ & $\begin{array}{c}\text { Thickness } \\
{[\boldsymbol{\mu \mathbf { m } ]}]}\end{array}$ & $\begin{array}{c}\mathbf{T C} \\
{\left[\mathbf{W} \cdot \mathbf{m}^{-\mathbf{1}} \cdot \mathbf{K}^{\mathbf{- 1}}\right]}\end{array}$ \\
\hline Epoxy & - & 80 & 0.15 \\
\hline AAO membrane & - & 60 & $1.3[20]$ \\
\hline Epoxy/AAO & 33 & 73 & 0.25 \\
\hline Epoxy/AAO-1000 & 38 & 76 & 1.06 \\
\hline Epoxy/AAO-1200 & 39 & 72 & 1.13 \\
\hline
\end{tabular}



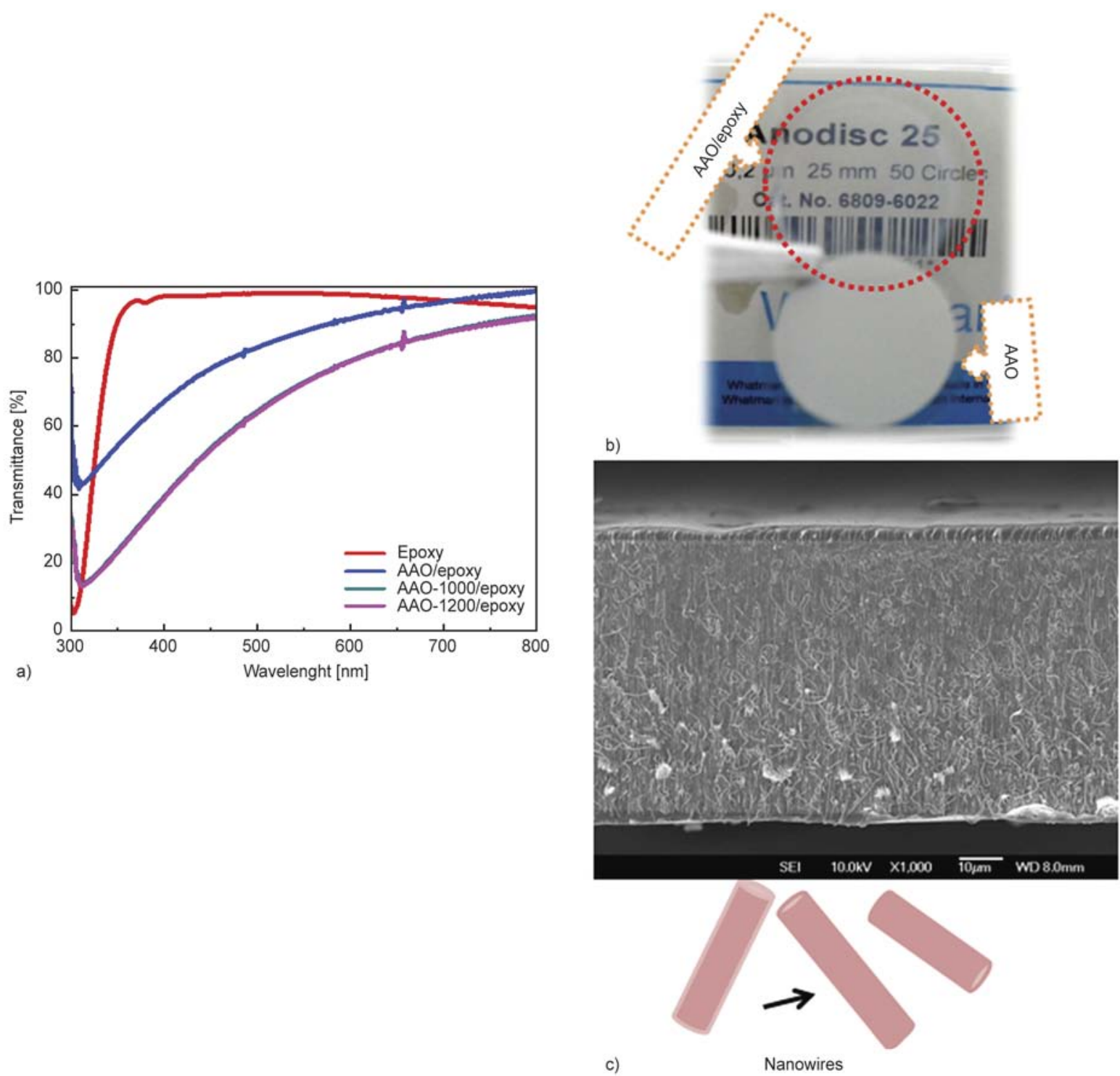

Figure 5. (a) Transmission spectra of annealed and unannealed AAO membrane and their nanocomposites, (b) a photograph of AAO membrane and AAO/epoxy composites (c) FE-SEM image of epoxy nanowires through the AAO thickness of AAO/epoxy nanocomposites

nanocomposites which has been reported till now. Thermal conductivity of composites enhanced more than 7 times while transmittance percentage $\left(T_{\lambda 550 \mathrm{~nm}}\right.$ [\%]) is about $70 \%$. It should be considered that, to get more accurate thermal conductivity results, thickness of samples should be close to thickness of AAO membrane $(60 \mu \mathrm{m})$.

\section{Conclusions}

In summary, we successfully prepared thermally conductive and transparent nanocomposites by a simple impregnation based method. Crystalline structure of annealed AAO membrane characterized by XRD. FE-SEM was selected to study the morpholigcal changes as a result of annealing. Filling the parallel pores of membrane with resin of similar refractive index and formation of polymeric nanowires through the sample thickness resulted in transparent nanocomposites. Through-plane thermal conductivity of composites enhanced as high as $1.13 \mathrm{~W} \cdot \mathrm{m}^{-1} \cdot \mathrm{K}^{-1}$ as a result of devitrification of the amorphous alumina membrane after annealing at $1200^{\circ} \mathrm{C}$. These types of nanocomposites can open new heat management approaches in small electronic devices, high power LED lightening devices and so on.

\section{Acknowledgements}

We would like to acknowledge department of polymer engineering of 'Korea National University of Transportation' for providing some facilities for us. 


\section{References}

[1] Cao D., Jensen S. D.: Led light source. U.S. Patent 13665689, USA (2013).

[2] Shimazaki Y., Hojo F., Takezawa Y.: Preparation and characterization of thermoconductive polymer nanocomposite with branched alumina nanofiber. Applied Physics Letters, 92, 133309/1-133309/4 (2008). DOI: $10.1063 / 1.2907315$

[3] Shimazaki Y., Hojo F., Takezawa Y.: Highly thermoconductive polymer nanocomposite with a nanoporous $\alpha$-alumina sheet. ACS Applied Materials and Interfaces, 1, 225-227 (2008).

DOI: $10.1021 / \mathrm{am} 800055 \mathrm{~s}$

[4] Zhou W.: Thermal and dielectric properties of the AlN particles reinforced linear low-density polyethylene composites. Thermochimica Acta, 512, 183-188 (2011). DOI: $\underline{10.1016 / \mathrm{j} . t c a .2010 .10 .003}$

[5] Hong J-P., Yoon S-W., Hwang T., Oh J., Hong S., Lee Y., Nam J.: High thermal conductivity epoxy composites with bimodal distribution of aluminum nitride and boron nitride fillers. Thermochimica Acta, 537, 70-75 (2012).

DOI: $10.1016 / \mathrm{j}$. tca.2012.03.002

[6] Song W-L., Wang P., Cao L., Anderson A., Meziani M., Farr A., Sun Y-P.: Polymer/boron nitride nanocomposite materials for superior thermal transport performance. Angewandte Chemie International Edition, 51, 6498-6501 (2012). DOI: $10.1002 /$ anie.201201689

[7] Yu J., Huang X., Wu C., Wu X., Wang G., Jiang P.: Interfacial modification of boron nitride nanoplatelets for epoxy composites with improved thermal properties. Polymer, 53, 471-480 (2012).

DOI: 10.1016/j.polymer.2011.12.040

[8] Yu J., Huang X., Wang L., Peng P., Wu C., Wu X., Jiang P.: Preparation of hyperbranched aromatic polyamide grafted nanoparticles for thermal properties reinforcement of epoxy composites. Polymer Chemistry, 2, 1380-1388 (2011). DOI: $10.1039 /$ C1PY00096a

[9] Yu J., Duan J., Peng W. Y., Wang L. C., Peng P., Jiang P. K.: Influence of nano-AlN particles on thermal conductivity, thermal stability and cure behavior of cycloaliphatic epoxy/trimethacrylate system. Express Polymer Letters, 5, 132-141 (2011).

DOI: 10.3144/expresspolymlett.2011.14

[10] Qian R., Yu J., Xie L., Li Y., Jiang P.: Efficient thermal properties enhancement to hyperbranched aromatic polyamide grafted aluminum nitride in epoxy composites. Polymers for Advanced Technologies, 24, 348 356 (2013).

DOI: $10.1002 /$ pat.3090
[11] Terao T., Bando Y., Mitome M., Zhi C., Tang C., Golberg D.: Thermal conductivity improvement of polymer films by catechin-modified boron nitride nanotubes. The Journal of Physical Chemistry C, 113, 13605-13609 (2009).

DOI: $10.1021 / \mathrm{jp} 903159 \mathrm{~s}$

[12] Terao T., Zhi C., Bando Y., Mitome M., Tang C., Golberg D.: Alignment of boron nitride nanotubes in polymeric composite films for thermal conductivity improvement. The Journal of Physical Chemistry C, 114, 4340-4344 (2010). DOI: 10.1021/jp911431f

[13] Shimazaki Y., Miyazaki Y., Takezawa Y., Nogi M., Abe K., Ifuku S., Yano H.: Excellent thermal conductivity of transparent cellulose nanofiber/epoxy resin nanocomposites. Biomacromolecules, 8, 2976-2978 (2007).

DOI: $10.1021 / \mathrm{bm} 7004998$

[14] Groner M. D., Fabreguette H. F., Elam J. W., George S. M.: Low-temperature $\mathrm{Al}_{2} \mathrm{O}_{3}$ atomic layer deposition. Chemistry of Materials, 16, 639-645 (2004). DOI: $10.1021 / \mathrm{cm} 0304546$

[15] Liu Y., Wang H. H., Indacochea J. E., Wang M. L.: A colorimetric sensor based on anodized aluminum oxide (AAO) substrate for the detection of nitroaromatics. Sensors and Actuators B: Chemical, 160, 1149-1158 (2011).

DOI: $10.1016 /$ j.snb.2011.09.040

[16] Tao P., Li Y., Rungta A., Viswanath A., Gao J., Benicewicz B. C., Siegel R. W., Schadler L. S.: $\mathrm{TiO}_{2}$ nanocomposites with high refractive index and transparency. Journal of Materials Chemistry, 21, 1862318629 (2011).

DOI: 10.1039/C1JM13093E

[17] Parker W., Jenkins R., Butler C., Abbott G.: Flash method of determining thermal diffusivity, heat capacity, and thermal conductivity. Journal of Applied Physics, 32, 1679-1684 (1961).

DOI: $10.1063 / 1.1728417$

[18] Lü C., Yang B.: High refractive index organic-inorganic nanocomposites: Design, synthesis and application. Journal of Materials Chemistry, 19, 2884-2901 (2009).

DOI: 10.1039/B816254A

[19] Cheng D. F., Yagihashi M., Hozumi A.: Lamination of alumina membranes to polymer surfaces: Thick, hard, transparent, crack-free alumina films on polymers with excellent adhesion. ACS Applied Materials and Interfaces, 3, 2224-2227 (2011).

DOI: $10.1021 / \mathrm{am} 200662 \mathrm{~d}$

[20] Zhou M., Lin T., Huang F., Zhong Y., Wang Z., Tang Y., Bi H., Wan D., Lin J.: Highly conductive porous graphene/ceramic composites for heat transfer and thermal energy storage. Advanced Functional Materials, 23, 2263-2269 (2013).

DOI: $\underline{10.1002 / \mathrm{adfm} .201202638}$ 